\title{
Loading rate effects on CFRP strengthened steel square hollow sections under lateral impact
}

DOI:

10.1016/j.engstruct.2018.04.066

\section{Document Version}

Accepted author manuscript

Link to publication record in Manchester Research Explorer

\section{Citation for published version (APA):}

Kadhim, M. M. A., Wu, Z., \& Cunningham, L. S. (2018). Loading rate effects on CFRP strengthened steel square hollow sections under lateral impact. Engineering Structures. https://doi.org/10.1016/j.engstruct.2018.04.066

\section{Published in:}

Engineering Structures

\section{Citing this paper}

Please note that where the full-text provided on Manchester Research Explorer is the Author Accepted Manuscript or Proof version this may differ from the final Published version. If citing, it is advised that you check and use the publisher's definitive version.

\section{General rights}

Copyright and moral rights for the publications made accessible in the Research Explorer are retained by the authors and/or other copyright owners and it is a condition of accessing publications that users recognise and abide by the legal requirements associated with these rights.

\section{Takedown policy}

If you believe that this document breaches copyright please refer to the University of Manchester's Takedown Procedures [http://man.ac.uk/04Y6Bo] or contact uml.scholarlycommunications@manchester.ac.uk providing relevant details, so we can investigate your claim.

\section{OPEN ACCESS}




\title{
Loading rate effects on CFRP strengthened steel square hollow sections under lateral impact
}

\author{
Majid M.A. Kadhim ${ }^{1}$, Zhangjian $\mathrm{Wu}^{2}$, and Lee S. Cunningham ${ }^{2}$ \\ ${ }^{1}$ College of Engineering, University of Babylon, Iraq \\ ${ }^{2}$ School of Mechanical, Aerospace and Civil Engineering, University of Manchester, UK
}

\begin{abstract}
Application of fibre reinforced polymer (FRP) composites has steadily gained popularity in rehabilitation of steelwork over the last decade or so. This popularity is based on the inherent advantages of FRP and the considerable amount of research conducted on the response of FRP strengthened steelwork members under static loads. However, over the course of their service life, steel structures can be subjected to impact loads induced by a variety of sources. This necessitates the requirement for a comprehensive study that can shed light on the behaviour of FRP strengthened steelwork under various loading rates.
\end{abstract}

This paper discusses the experimental results of carbon fibre reinforced polymer (CFRP) strengthened square hollow sections (SHS) under different loading rates. The experiments comprised a series of SHS columns tested under two loading rates: quasi-static $(0.05 \mathrm{~mm} / \mathrm{sec})$ and impact $(4.43 \mathrm{~m} / \mathrm{sec})$. Some of these columns were strengthened with different CFRP configurations comprising fibres oriented in the longitudinal direction, transverse direction and in both directions. The effect of coexisting axial compression applied prior and during the application of the transverse load (impact or quasi-static) was also examined. The axial load was introduced in the experimental program to simulate the normal service load that exists on columns in multi-storey frame buildings. Generally, it was found that the effectiveness of CFRP strengthening was increased at a higher loading rate to different degrees depending on the CFRP configuration.

\section{Introduction}

During their service life, steel structures may be subjected to impact actions from different sources such as vehicle collisions, debris, rock-falls, and blast events. Impact is often characterised by large load amplitudes applied within a short duration which in turn cause strain rate effects in the materials and inertia effects in the structure. These effects make the behaviour of structures under impact loading different from that under static loading. Fibre reinforced polymer (FRP) composites have been commonly employed in the field of civil engineering for the last two decades or so. Correspondingly, the response of FRP strengthened steel structures under quasi-static loading rates has been widely covered [1-3]. To date, structural behaviour of steel members strengthened with FRP under impact loading is limited to a very few exploratory studies $[4,5]$. Thus, much uncertainty still 
exists surrounding the differences between the structural behaviour of these kinds of strengthened members under impact.

As mentioned previously, the response of CFRP strengthened steel members has widely been investigated under static load. For example, Shaat and Fam [6] found that the increase in the ultimate load of CFRP strengthened slender SHS steel columns ranged from $6 \%$ to $71 \%$ compared to the corresponding un-strengthened case, depending on the slenderness ratio. Similarly, it was found that the ultimate load of CFRP strengthened lipped channel steel columns increased by about $15 \%$ to $20 \%$ compared to the corresponding un-strengthened columns for short and long columns respectively [7]. However to date, the behaviour of CFRP strengthened steel columns under impact load has been only lightly investigated. In one of the few existing studies, Alam and Fawzia [8] numerically investigated the response of axially compressed CFRP strengthened columns under transverse impact. Another study conducted by Kadhim et al. [4] investigated the numerical response of a CFRP strengthened steel column under impact load. Both studies showed that this strengthening technique could effectively reduce the transverse displacement of columns by around $60 \%$ and $40 \%$ for the former and latter studies respectively. The main difference between these studies was the omission of the effects of the partial bond between CFRP and the steel section by the former study. A further numerical study was carried out by the authors of the present paper [5] in which the structural behaviour of I'section steel beams strengthened with various length and thickness of CFRP laminate was investigated. It was found that the application of CFRP can reduce the deflection of steel beams by around 13\% compared to the corresponding un-strengthened beam.

Recently, two experimental studies were published on the behaviour of CFRP strengthened steel hollow sections under impact load [9, 10]. In the first study [9], strengthening of square hollow sections was examined with different CFRP configurations comprising fibres oriented in the longitudinal, transverse and both longitudinal and transverse directions. One of the main contributions of this study was the effect of axial pre-compression which represented pre-existing axial load on the columns prior to applying the impact load. In the latter study [10], circular hollow sections (CHS) were strengthened with different CFRP configurations including fibres oriented in the longitudinal direction and in both longitudinal and transverse directions. In both of these studies, the CFRP strengthening technique was found to be able to reduce the transverse displacement by around $32 \%$ and $29 \%$ for the former and latter studies respectively. It should be noted that different adhesive materials, namely Araldite 420 and Mbrace 4500, were used in the former and latter studies respectively. In regards to adhesive, some of the previous studies [11,12] that have been conducted on CFRP-steel joints recommended the use of Araldite 420 as an adhesive material for CFRP-steel joints in the case of impact loads due to their nonlinear behaviour. The current study makes a comparison between the effectiveness of CFRP under various loading rates (impact and quasi-static) 
which has not been investigated elsewhere. The previously referred to studies $[9,10]$ have tested a series of strengthened samples under impact loading rate only.

In terms of comparing the contribution of the CFRP strengthening technique under various loading rates, to date there are no readily available studies focussing on this particular parameter in steel square hollow sections under lateral impact. An axial crushing test for CFRP strengthened spotwelded thin-walled steel SHSs was performed under quasi-static and impact loading rates [13]. The test was conducted to ensure the applicability of steel-CFRP in the automotive industry. The test results demonstrated that the benefit of the application of CFRP to spot-welded SHSs was significant and was much more pronounced in the quasi-static tests than in the impact tests. The comparison was made in terms of crush load, specific energy and structural effectiveness factor. The reduction in the contribution of the CFRP strengthening technique was due to the extensive debonding that occurred in the impact tests. Such kind of failure reduces the ability of the steel-CFRP to absorb energy. This kind of debonding is expected since a brittle type of adhesive material (MBrace) was used and this is less sensitive to strain rate compared with other adhesives such as Araldite 420 as experimentally observed in $[12,14]$.

Based on the aforementioned discussions the behaviour of CFRP strengthened steel members under both quasi-static and to a lesser extent impact loading has been considered. However, what is not yet understood is the difference between the effectiveness of CFRP under various loading rates. The main aim of the present study is to compare the structural response of SHS steelwork strengthened with specific CFRP configurations at different loading rates. By understanding the response of this strengthening technique under various loading rates, ultimately a design guide can be established for different loading rates thus allowing practitioners to benefit from the considerable advantages this technique can offer $[6,9]$. The work presented here is an extension of a preliminary study on rectangular hollow sections conducted by the authors [15]. The current paper presents a more extensive set of results and provides a new investigation of key parameters not dealt with in the previous paper [15]. Generally, it is well known that when the loading rate is increased the plastic flow stress of a steel section is also increased because of the strain rate effect. However, the increment in the member's strength is usually dependent on the strain rate sensitivity of the member's material. When strengthened with CFRP, strain rate sensitivity, plastic flow and the failure mode of the section may be different from the corresponding un-strengthened section. These effects will be explored quantitatively in the current experimental investigation. 


\section{Experimental setup}

\subsection{CFRP strengthened SHS samples}

The experimental programme comprised the testing of ten samples under various loading rates. Square hollow sections (SHS) with dimensions $40 \mathrm{~mm} \times 40 \mathrm{~mm} \times 3 \mathrm{~mm}$ of steel grade S355 were used to make $0.85 \mathrm{~m}$ long samples. Two end plates were welded to each end to allow attachment of the samples to the testing rig. CFRP was bonded to six samples while the rest of the samples were tested without strengthening for comparison purposes. All strengthened columns had CFRP wrapped around all four faces over the $800 \mathrm{~mm}$ length. In each of the strengthened samples, the CFRP strengthening consisted of 2 plies, each with a thickness of $0.6 \mathrm{~mm}$. Each of the two plies were oriented either in the same direction (for the samples strengthened in the longitudinal direction and samples strengthened in the transverse direction) or in both directions (for samples strengthened in both directions). In other words, the overall thickness and mass of the CFRP strengthening was kept constant (1.2mm in total) for all strengthened samples in all configurations in order to verify the effectiveness of each configuration. In the case of the samples strengthened in both directions, it should be noted that the layer with fibres oriented in the longitudinal direction was applied first followed by the second layer, i.e. the layer with fibres oriented in the transverse direction was outermost. For the samples strengthened with CFRP oriented in the transverse direction (CTT samples in Table 1) and with CFRP oriented in both longitudinal and transverse direction (CLT samples in Table 1), the CFRP ply was wrapped in the transverse direction having a $25 \mathrm{~mm}$ overlap to avoid premature failure in the joints of the transverse ply in accordance with the recommendations of [13].

In total, five samples were tested under a quasi-static loading rate $(0.05 \mathrm{~mm} / \mathrm{sec})$ and another five were tested under a low-velocity impact rate $(4.43 \mathrm{~m} / \mathrm{sec})$. The effect of preloading level (indicated by the ratio of applied load / ultimate design load for the column, [16]) was also investigated in this experiment as listed in Table 1. The samples were tested under two preloading conditions namely zero preloading and a 50\% preloading level which represents a moderate load level commensurate with in-service loading in a real structure. The following naming system is employed to describe each sample: the first letter (C) stands for the column, the second pair of letters (LL, TT or LT) denotes the orientation of fibres in each of the two CFRP layers used to strengthen the sample i.e. longitudinal, transverse and both longitudinal and transverse directions, respectively, and the last numeric value 0 and 50 denotes the preloading level (percentage). For example, CLL50 means that the column was strengthened with 2 layers of CFRP with fibres oriented in the longitudinal direction and tested under transverse impact load while 50\% preloading was applied. Note that the first letter "S" for the samples listed in Table 1 refers to static (or more accurately quasi-static loading here). 


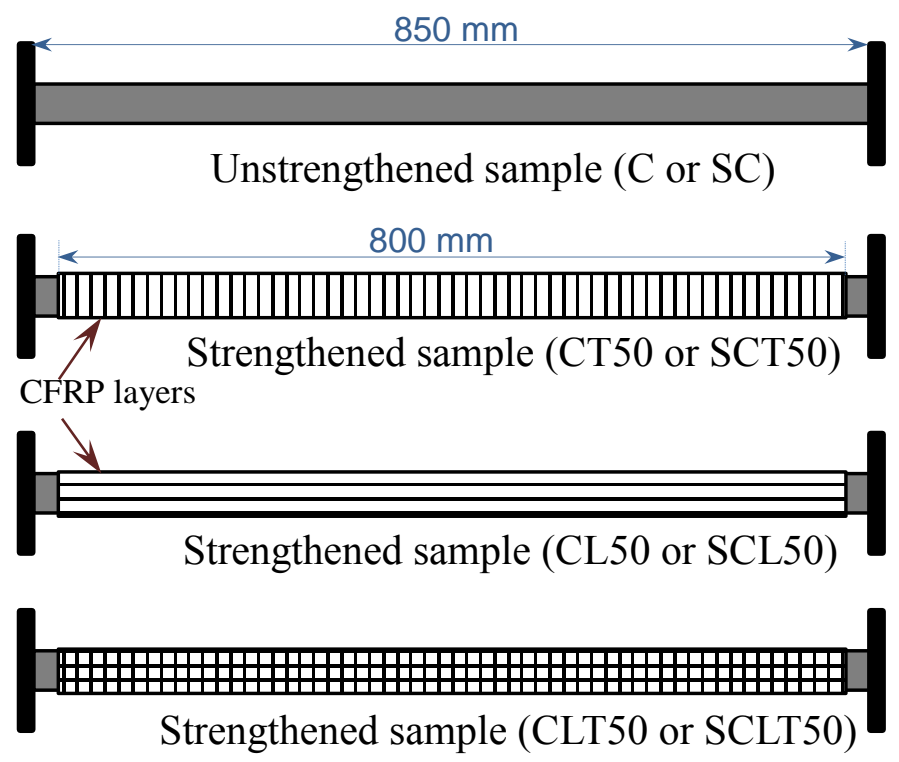

Figure 1. Sample configuration.

Table 1 Sample identification

\begin{tabular}{llll}
\hline Preloading level (\%) & CFRP configuration & Preloading level (\%) & Loading rate (m/sec) \\
\hline C0 & - & 0 & 4.43 \\
SC0 & - & 0 & $0.05 \times 10^{-3}$ \\
C50 & - & 50 & 4.43 \\
SC50 & - & 50 & $0.05 \times 10^{-3}$ \\
CLL50 & Longitudinal & 50 & 4.43 \\
SCLL50 & Longitudinal & 50 & $0.05 \times 10^{-3}$ \\
CTT50 & Transverse & 50 & 4.43 \\
SCTT50 & Transverse & 50 & $0.05 \times 10^{-3}$ \\
CLT50 & Longitudinal+ transverse & 50 & 4.43 \\
SCLT50 & Longitudinal+ transverse & 50 & $0.05 \times 10^{-3}$ \\
\hline
\end{tabular}

\subsection{Material properties and sample arrangement}

The stress-strain curves for the investigated cold-formed steel hollow sections were obtained through tensile coupon tests. Three coupons were taken from the parent steel section and were then tested in accordance with ASTM E8/E8M-9 [17]. The average yield and ultimate stresses were 538.8 and 611.1MPa respectively. The average modulus of elasticity was $185 \mathrm{GPa}$. CFRP coupon specimens were prepared from the unidirectional CFRP commercially named Toho Tenax STS40 and tested according to ASTM3039-00 [18] to obtain the tensile properties of the CFRP. The measured tensile strength, ultimate strain and elastic modulus were $1397.8 \mathrm{MPa}, 0.014$ and $105.3 \mathrm{GPa}$ respectively. Adhesive material commercially known as Araldite 420 was used to bond the CFRP plies to the steel surfaces The mixing ratio of this adhesive material was (2.5: 1) of component A and component $\mathrm{B}$ by weight [19].The elastic modulus and tensile strength of Araldite 420 are $1.495 \mathrm{GPa}$ and $29 \mathrm{MPa}$ respectively as reported by the manufacturer [19]. 
In order to avoid adhesion failure, special attention was given to surface preparation. Firstly, the steel surface was wiped with acetone to remove contaminants on the surface such as grease and oil. Mechanical abrasion using an abrasive wheel, which is usually employed to remove the weak oxide layer and to roughen the surface for good adhesion, was then performed as shown in Figure 2. Following this, the abraded surface was cleaned with acetone to remove any grease or oil before applying the CFRP layer. At this stage, several post-yield strain gauges were affixed at certain locations. In this research, a wet lay-up technique [12] was used to fabricate the CFRP strengthened steel samples by bonding unidirectional carbon fibre sheets using Araldite 420 adhesive. These carbon fibre sheets were then wiped with acetone to remove dust. A layer of Araldite 420 was applied on the steel surface using a brush. Efforts were made to ensure that the adhesive layers on all specimens were of a uniform thickness. However, a 100\% uniform adhesive layer thickness is impossible to achieve in practice when using the wet lay-up technique [12]. This was followed by saturating a ply of carbon fibre sheet with the adhesive material using a brush, before applying the saturated layer onto the adhesive-steel surface. A bristle roller was then used to eliminate small air bubbles and pin-holes. The same procedure was then used to add the rest of the layers. The samples were cured at room temperature for at least seven days, as per the resin manufacturer's instructions. The $5 \mathrm{~mm}$ strain gauges were finally mounted onto the CFRP surface. It was found that the average thickness of the adhesive layer was $0.88 \mathrm{~mm}$ with a deviation of $+/-0.2 \mathrm{~mm}$ along the sample length.

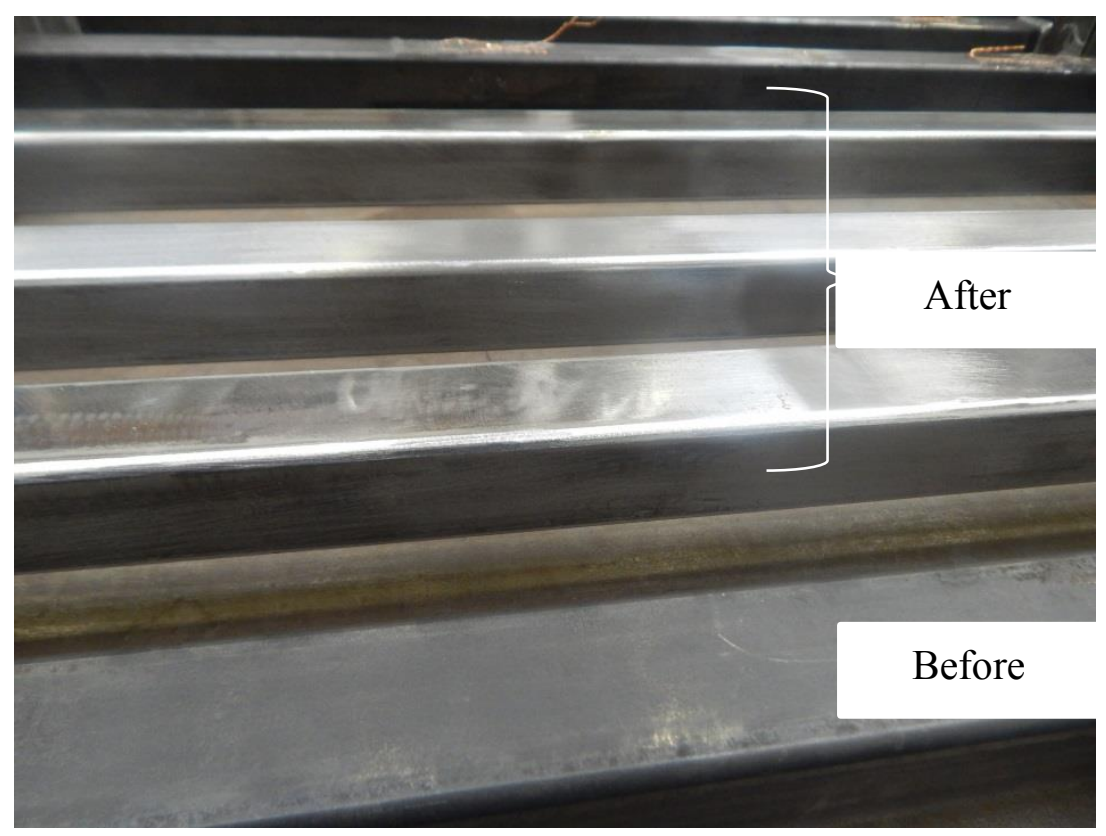

Figure 2. Surface preparation of the tested samples.

\subsection{Test setup}

In order to apply the pre-compression load prior to and during the test, a special test rig was manufactured. A disc spring pile was used to apply the pre-compression load on the samples as shown 
in Figure 3. A $650 \mathrm{kN}$ capacity Kistler load cell was positioned in the striker system under precompression to reduce the effect of vibration on the load cell. This load cell was used to record the impact force with time. The test rig can provide fixed end type (while allowing axial movement in the axial direction at one end) boundary conditions. In the both static and impact tests, the load was applied to the striking system (see Figure 3) which was then transferred to the sample by an indenter. The indenter was made from high-strength steel (EN24). The head of the indenter was rounded with a $2 \mathrm{~mm}$ radius to avoid local failure in the specimens as recommended by [20]. The shape of indenter was also chosen to represent the type of sharp edges associated with a vehicle collision since this kind of impact source is one of the most common on structural elements. Six strain gauges were mounted on each sample as shown in Figure 4 to measure the strain profile during the test. All strain gauges were attached in the longitudinal direction apart from strain gauge G1 which was mounted in the transverse direction on the lateral side of the samples under the indenter in order to measure the local strain in this direction and thus indicate the effect of the CFRP (in the transverse direction) on local deformation of the steel section. The impact load was applied via a $91 \mathrm{~kg}$ impactor dropped from a $1 \mathrm{~m}$ height to provide a $4.43 \mathrm{~m} / \mathrm{sec}$ velocity by use of a hammer machine which has a $150 \mathrm{~kg}$ mass capacity and a $5 \mathrm{~m}$ maximum drop height. This value of velocity was chosen to be in the range of the velocities commonly used by other researchers $[10,21]$. It should be mentioned that the overall recorded time during the tests was $0.05257 \mathrm{sec}$ in the impact tests with one reading taken every $0.000001 \mathrm{sec}$. The static tests were performed by operating the test rig on an RDP Group 200kN capacity universal testing machine, with a crosshead speed of $0.05 \mathrm{~mm} / \mathrm{sec}$. 


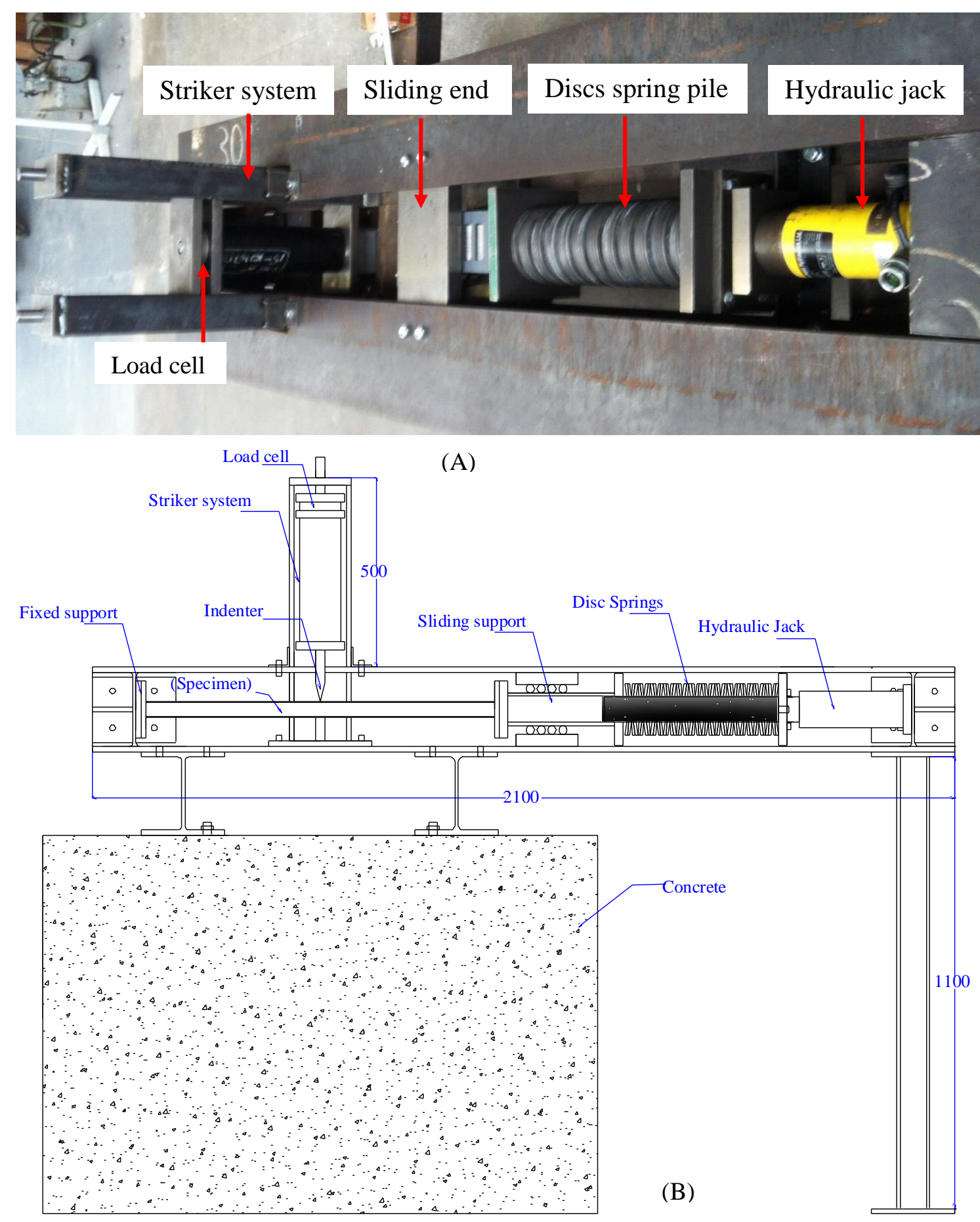

Figure 3. The test rig. (A) Oblique plan view; (B) Schematic view. 


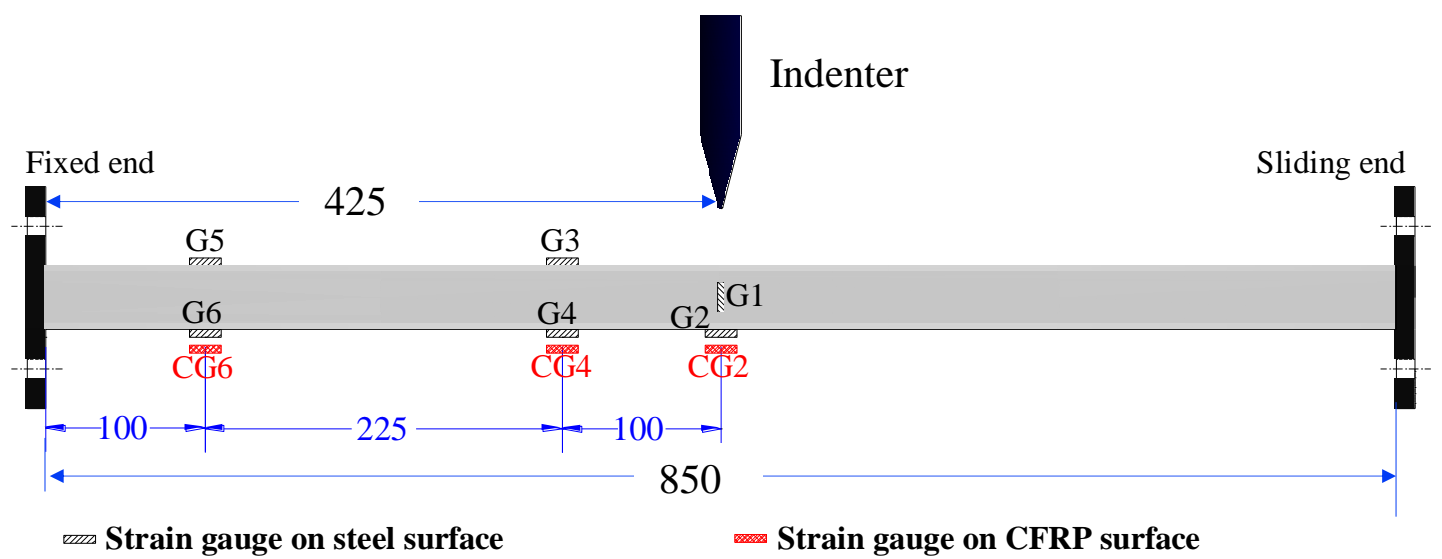

Figure 4. Strain gauge positions.

\section{Results}

\subsection{Force- transverse displacement}

The impact test was conducted under a constant impact energy which was generated by a $91 \mathrm{~kg}$ mass dropped with $4.43 \mathrm{~m} / \mathrm{sec}$ velocity as mentioned in Section 2, while in the quasi-static test the samples were loaded up to their ultimate load. Figure 5 illustrates that the initial peak force did not have a clear trend due to presence of the CFRP on the outer surface of the samples, which dampened the contact interaction and lowered the frequencies contributing in the reduction of the initial peak force Similar observations were reported by Shakir et al. [22] who tested a series of CFRP strengthened concrete filled steel tubes under impact load. It was found that applying CFRP in the impact region caused a reduction in the peak impact force. The same effect may also cause a delay in the time of the initial peak force due to the non-uniform outer surface (see Figure 5). After this peak force the vibration stage started, this is caused by the indenter at its first contact with the sample and may be induced the severe vibrations of both the sample and the indenter. These vibrations have in turn led to a rapid change in the contact force which is shown on the force-displacement plot as smaller amplitude spikes than that of the initial peak. Subsequently, the sample and impactor remain in contact and move together. During this stage, the impact force is nearly constant (here described as the "plateau stage"). During this stage, most of the impact energy is dissipated due to the relatively long duration compared to the other stages [5]. When the sample reaches the maximum transverse displacement, the sample and impactor rebound, this is referred to as the "unloading stage". However, the comparison between the plateau values of the un-strengthened samples tested under 0 and $50 \%$ preloading levels demonstrated that the plateau value reduced when applying axial force on the sample. Regarding the strengthened samples, it can be seen from Figure 5 that the samples strengthened with fibres oriented in both directions had higher plateau values compared to other 
strengthened samples. This reflects the higher contribution in maximising the plateau value when this configuration is used.

In terms of transverse displacement, it can be seen from Figure 5 that the strengthened samples always have less displacement in comparison with the un-strengthened samples (C50). This reduction in the transverse displacement as a result of applying CFRP varied with orientation of the CFRP layers. It was found that applying CFRP in the transverse direction has the minimum contribution compared to other configurations, while using fibres in both directions provides the higher contribution. This is due to the ability of this configuration in preventing local and global buckling [9]. Regarding the preloading level, it was also found that in absence of the pre-compression load the SHS sample had lower transverse displacement as shown in Figure 5.

Concerning the samples tested under quasi-static loading, Figure 6 shows the load-transverse displacement up to the corresponding ultimate load. In similarity to the trend discussed in the previous paragraph, the un-strengthened sample tested without applying pre-compression force achieved an ultimate load more than the corresponding value of the sample tested with a 50\% preloading level. In addition, the increment of the load-carrying capacity of specimen SCLT50 is about $26 \%$ compared to the un-strengthened sample (SC50), which is higher than the rest of the strengthened samples, while in sample SCTT50 the increase in the load-carrying capacity is around $11 \%$ in comparison with sample SC50.

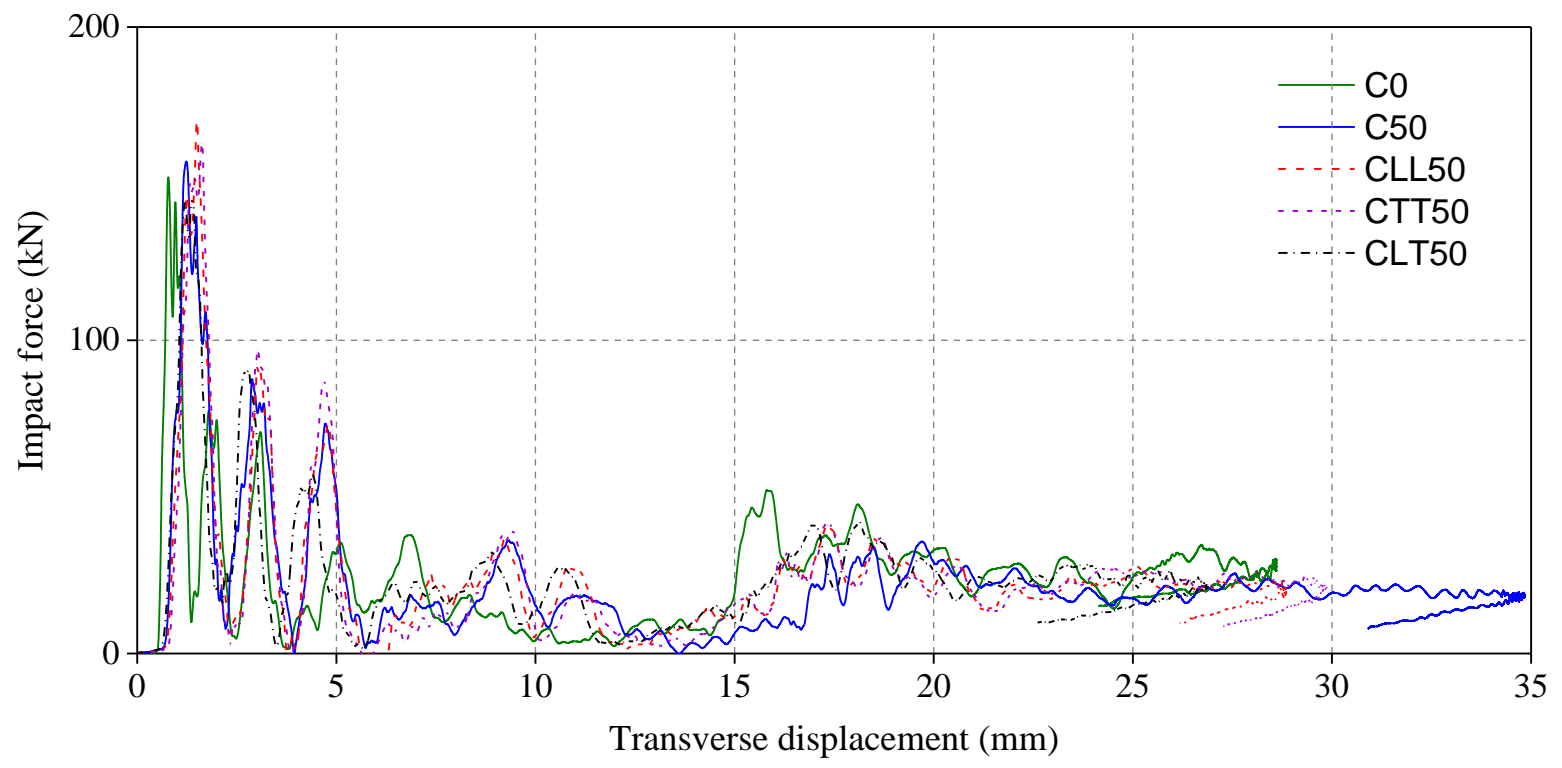

Figure 5. Impact force-transverse displacement at mid-span for samples tested under impact load. 


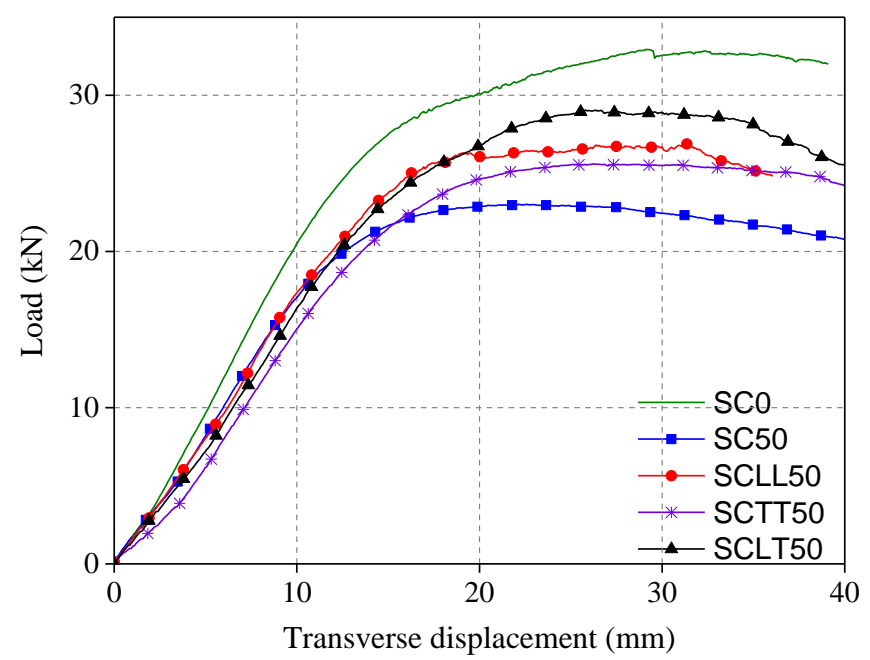

Figure 6. Load-transverse displacement at mid-span for samples tested under static load.

\subsection{Absorbed energy}

The absorbed energy in a sample is represented by the area under the load-transverse displacement curve as shown in Figure 7. In the case of the quasi-static loading rate, the total amount of energy imparted to the samples was not equal since the load was applied up to each sample's ultimate load. In other words, the applied energy to the samples was unequal. In the case of impact loading rate, the applied energy to the samples equals the potential energy of the drop hammer which is a function of its mass, acceleration due to gravity and the height from which it was dropped and the external work resulting from the pre-compression force in the axial direction. As mentioned in the beginning of Section 3, the potential energy of the drop hammer was identical but the external work for the all samples was not equal due to their unequal axial displacement. The value of the axial displacement varied with variation of the transverse displacement of each sample.

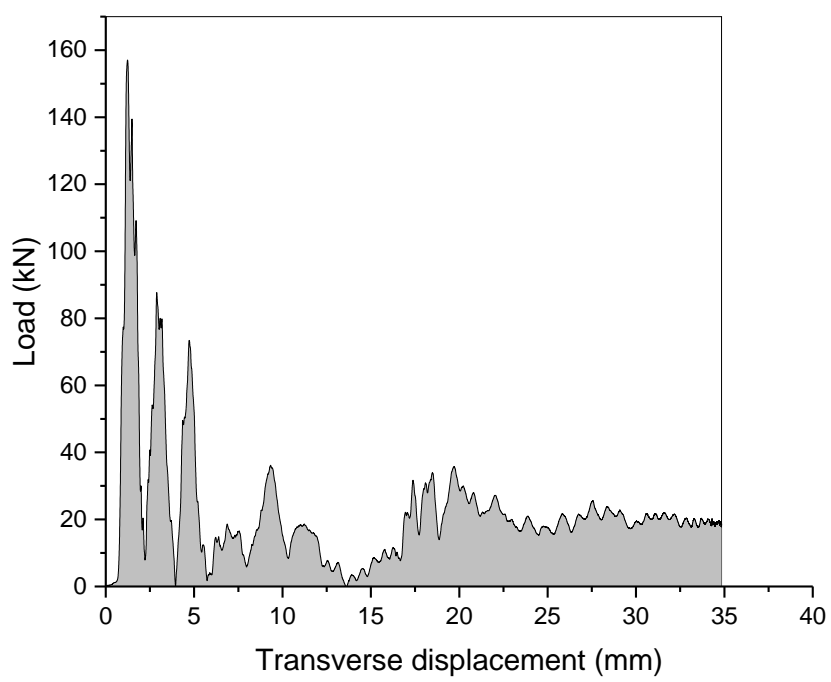

Figure 7. Typical load-transverse dispalcement relationship (C50) 
The absorbed energy of the samples tested under impact loading rate is plotted against the transverse displacement in Figure 8. This figure demonstrates that the maximum amount of the absorbed energy for the tested samples was different as discussed in the previous paragraph. It can also be seen from this figure that the maximum transverse displacement at the mid-span of these samples was not equal (Figure 5). For the samples tested under quasi-static loading, pre-loading will lead to larger transverse displacement under the same energy absorption as shown in Figure 9.

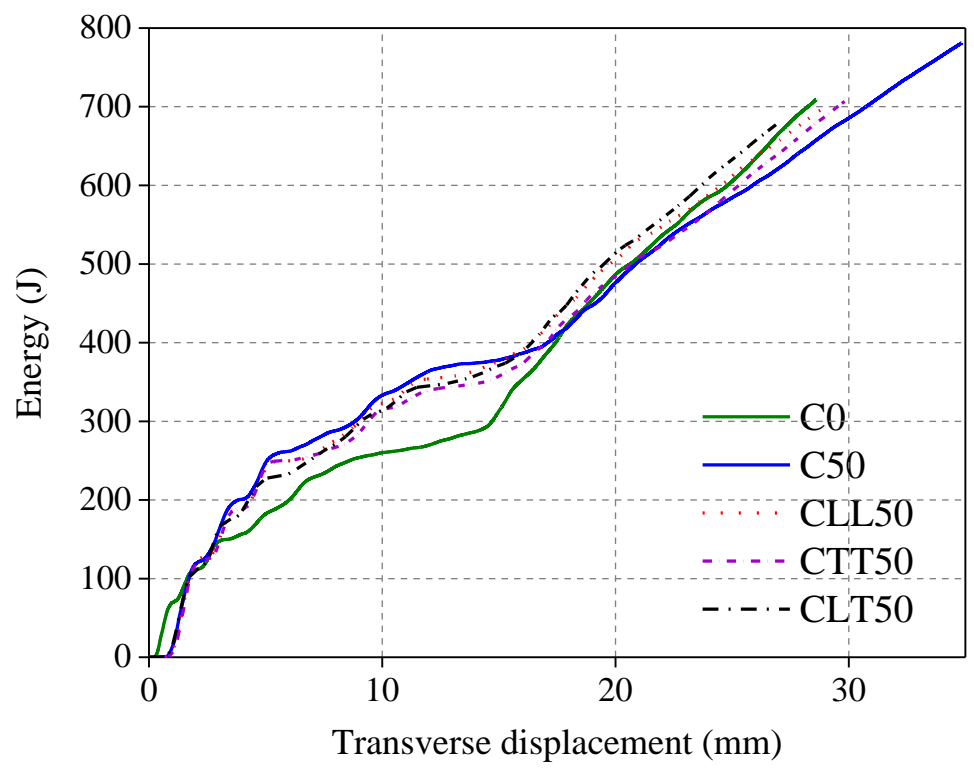

Figure 8: Absorbed energy for the samples tested under impact load.

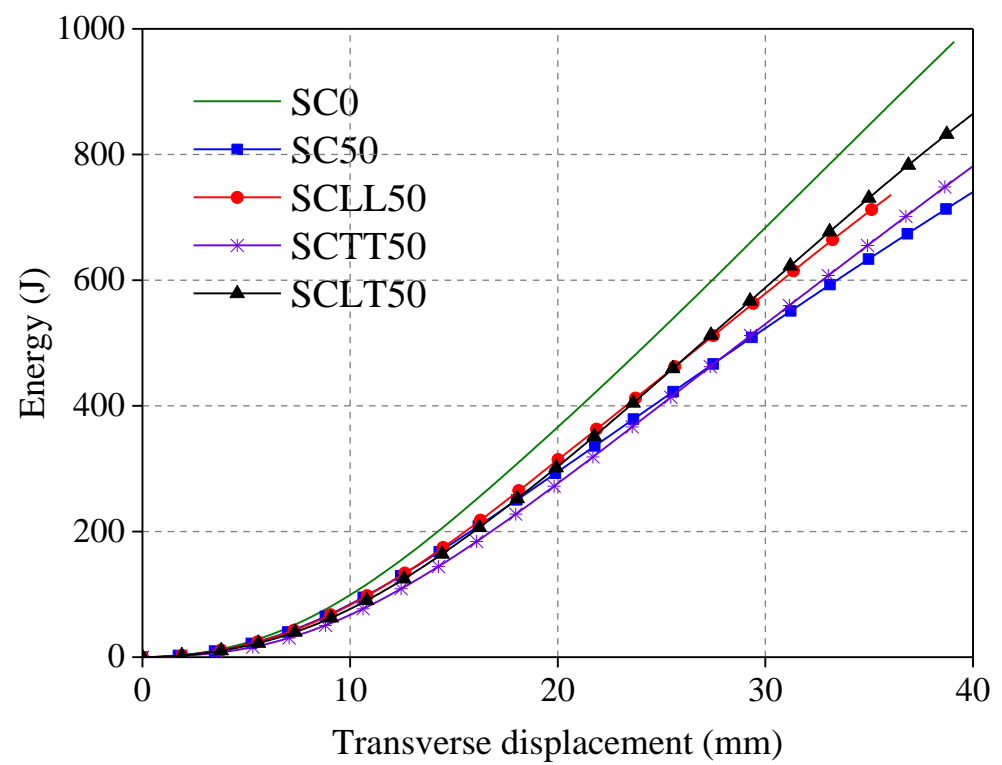

Figure 9. Absorbed energy for the samples tested under static load. 


\subsection{Failure mode}

It was mentioned earlier in subsection 3.1 that in the static test the samples were loaded up to their failure load while in the impact test a constant impact energy was applied to the samples. The samples tested under impact loading did not show any global failure. However, some local damage occurred in these samples in the impact region (see Figure 11). This damage could include local deformations in the steel section, CFRP rupture and CFRP debonding. The practical test results show that the local deformations in the steel comprised an inward indentation on the top and bottom surfaces and outward deformation at the sides of the section. Apart from this local damage there was no failure, delamination or debonding in evidence at any point in the tested samples.

In the case of the quasi-static loading, all tested samples failed in combination failure mode i.e. the tested samples in the beginning exhibited local deformation in the loading region which continued until plastic hinges were formed leading to global failure. This was then followed by extensive local failure as shown in Figure 10. This local failure caused a descent in the load vs. transverse displacement in the tested samples (see Figure 6) after the peak load. All samples exhibited a similar behaviour in the loading region which was identical to that which occurred in the impact test.
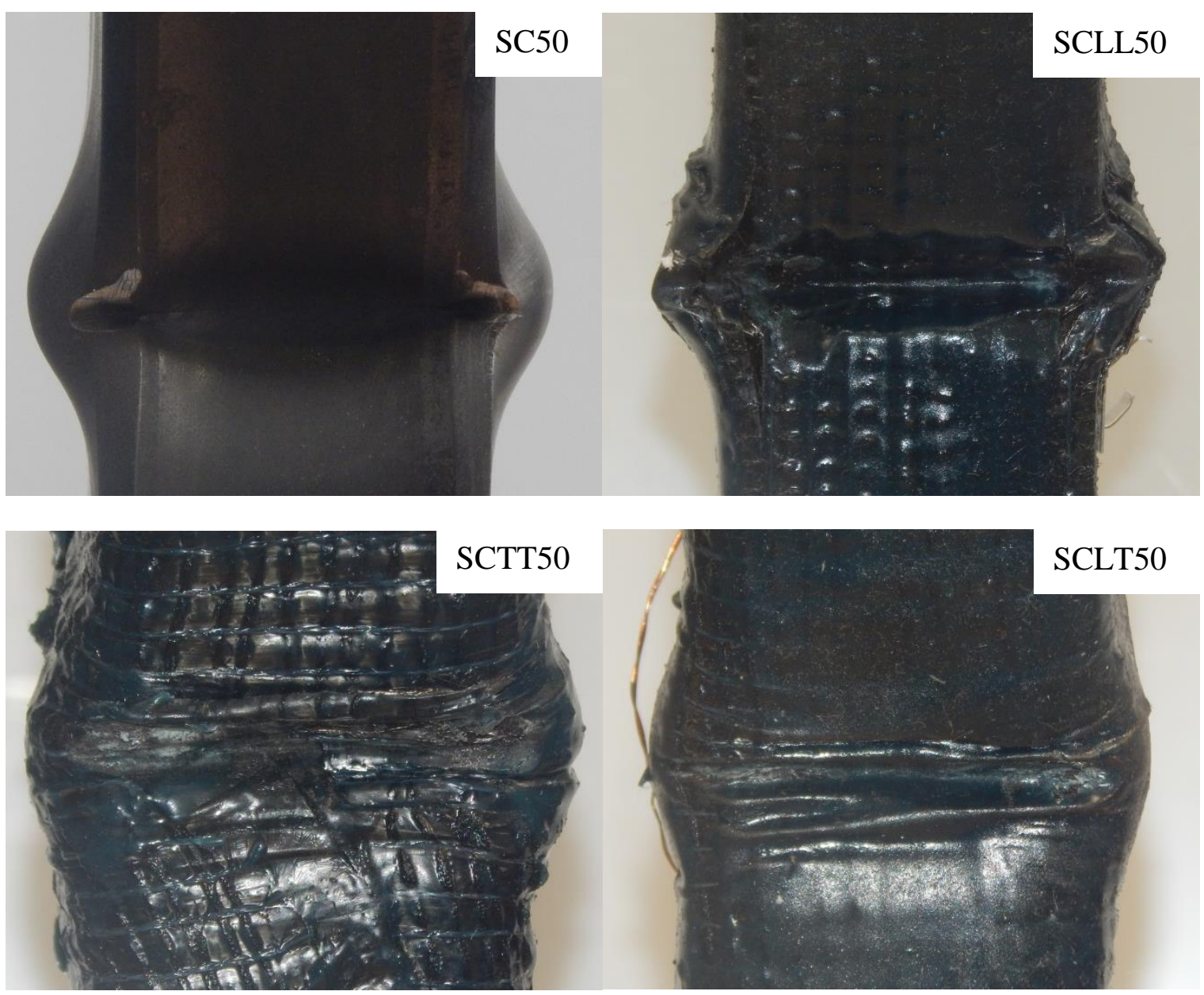

Figure 10. Failure mode for the samples tested under quasi-static loading rate 


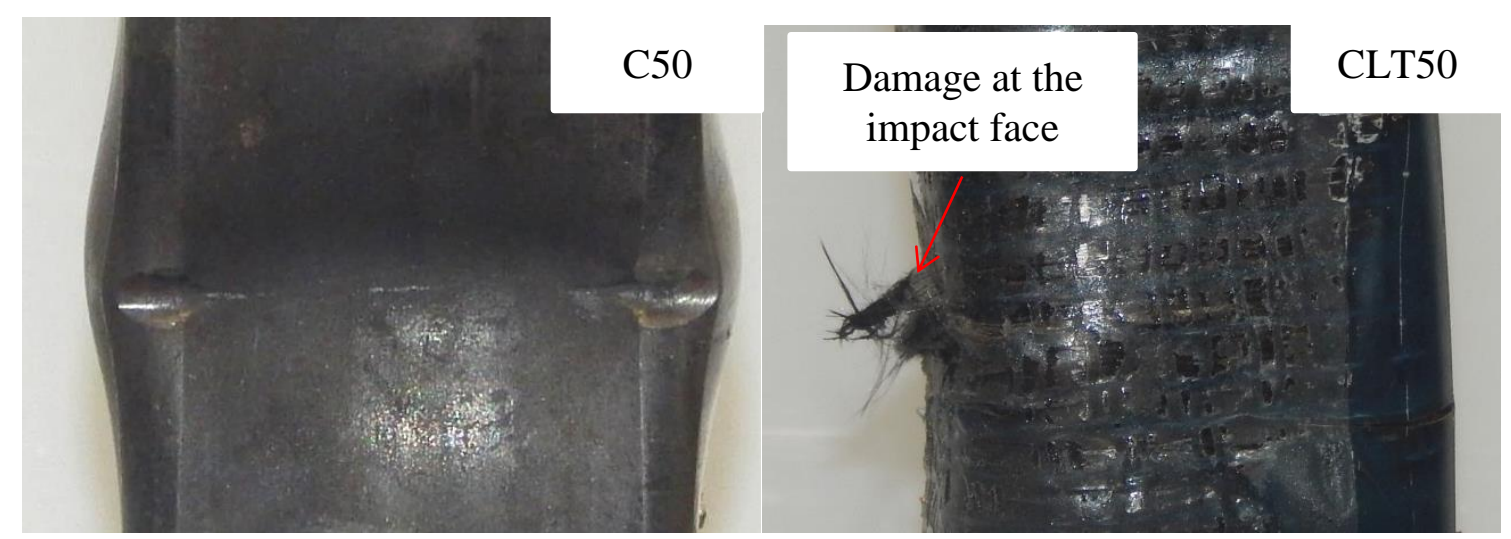

Figure 11. Failure mode for the samples tested under impact loading rate

\section{Comparison between static and impact results}

The general response trend of both loading rates is usually similar. For example, it was found the columns strengthened with fibres oriented in both directions had the maximum load-carrying capacity (or plateau force for the impact tests) and the minimum transverse displacement compared to the other corresponding columns. However, there were some differences regarding the amount of applied work on both loading rates. In other words, in the static tests the samples were loaded up to their ultimate load, while in the impact tests constant impact energy was applied to all samples. For example, the total energy absorbed by samples SC50 and C50, which is represented by the area under the forcetransverse displacement curve, was $960 \mathrm{~J}$ and $783 \mathrm{~J}$ respectively. Thus, the comparison between the static and impact tests should be undertaken based on a datum. Table 2 presents the energy absorbed by the samples up to $27 \mathrm{~mm}$ mid-span transverse displacement. The limit of $27 \mathrm{~mm}$ was chosen because this was the maximum transverse displacement that occurred for sample CLT50. All other samples have a maximum transverse displacement at mid-span larger that this value. This comparison might not be very fair because other samples (tested under impact load) reached the $27 \mathrm{~mm}$ transverse displacement at different times, which means that they have different strain rates when the comparison is made. However, bearing these differences in mind it might be worthwhile to have some basic comparisons between this set of tests.

Table 2 reveals that the energy absorbed by the sections tested under impact loading was greater than the corresponding values gained from the static test, for either strengthened or unstrengthened samples, this was clearly caused by the strain rate effects. It was further observed that the difference between the absorbed energy (impact and static) for the samples tested without pre-compressive load (C0 and SC0) was less than the associated values for the 50\% pre-compressed columns (C50 and SC50). This might relate to the fact that the average strain rate was greater for the samples tested under $50 \%$ preloading compared to those without. The strain rate has a significant effect on both the behaviour of steel and the steel reinforced with CFRP. Under the same loading rate for dynamic impact, the test results show that the energy absorbed for the 50\% pre-loading level strengthened 
sections is comparable to that of zero preloading unstrengthened steel sections. The specimens strengthened with CFRP generally have a higher energy absorption recovery.

It should be mentioned that the strain rate has a significant effect on both the behaviour of steel and the specific type of adhesive material used (Araldite 420) as previously reported by other researchers such as [23] and [14]. For the CFRP material itself, it is unclear if the strain rate has an effect on its behaviour or not. Some researchers have suggested that the effect of strain rate for unidirectional CFRP could be neglected [24, 25], while others have argued for the opposite [14]. Al-Zubaidy et al [14] have suggested a series of empirical formulae which could be used to evaluate possible CFRP response under various strain rates. The formulae describe the tensile dynamic properties of unidirectional CFRP sheets including tensile strength, elastic modulus and strain to failure under various strain rates. These equations are as follows:

$$
\begin{aligned}
& \sigma_{\text {dynamic }}=\sigma_{\text {static }}\left(1+4.496 \times 10^{-4} \&^{529}\right) \\
& E_{\text {dynamic }}=E_{\text {static }}\left(1+5.634 \times 10^{-3} \&^{8228}\right) \\
& \varepsilon_{\text {dynamic }}=\varepsilon_{\text {static }}\left(1+5.723 \times 10^{-7} \&^{89}\right) \ldots \ldots .
\end{aligned}
$$

Where $\sigma_{\text {static }}, E_{\text {static }}$ and $\varepsilon_{\text {static }}$ and $\sigma_{\text {dynamic }}, E_{\text {dynamic }}$ and $\varepsilon_{\text {dynamic }}$ are the static and dynamic tensile strength, elastic modulus and strain to failure of CFRP respectively, and \& \&is the strain rate. It should be noted equations (1) to (3) can only be applied for strain rates ranging from 0.000242 to $87.4 \mathrm{sec}^{-1}$ [14].

As previously mentioned, in the current study a number of strain gauges were positioned on the CFRP surface for each of the strengthened samples to measure the strain profile. These strain gauge readings can also be used to evaluate the strain rate occurring throughout the test duration. For instance, the average strain rate indicated by strain gauges CG2 and CG4 for sample CLL50 is plotted in Figure 12. 


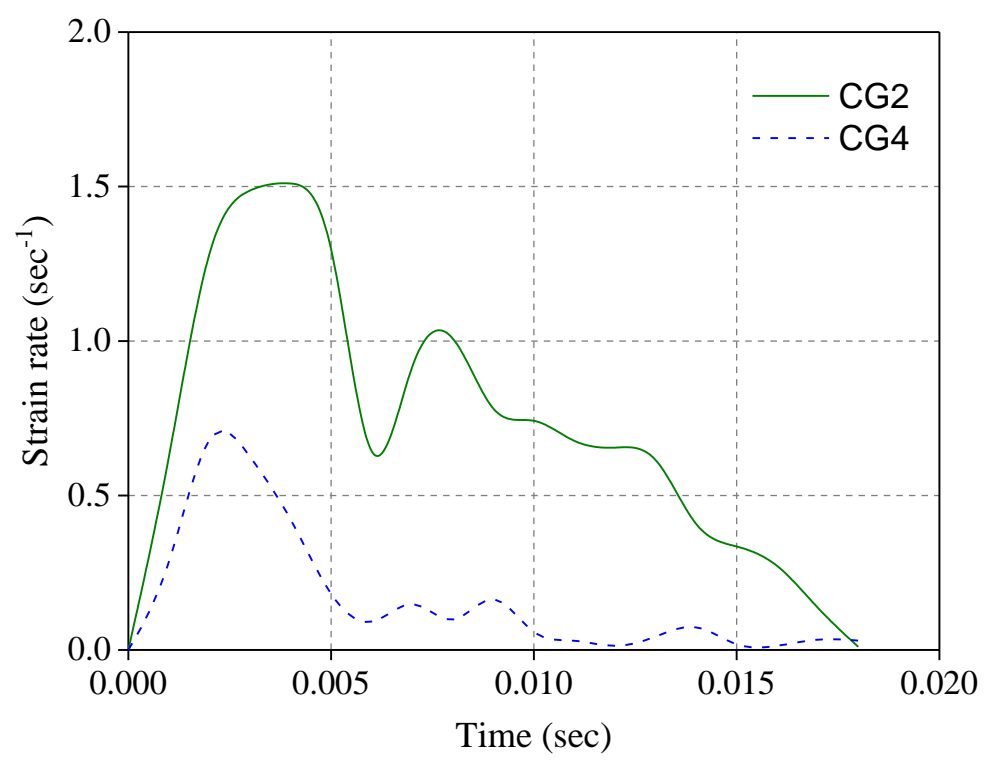

Figure 12. Strain rate during impact test vs. time for CLL50

It can be seen from this figure that the maximum strain rate occurring during the impact test duration was less than $2 \mathrm{sec}^{-1}$. If this value is applied to equations (1) to (3) the theoretical increase in the value of the tensile strength, elastic modulus and strain to failure is $0.1 \%, 1 \%$ and $0 \%$ respectively (see Table 3) when comparing these values under both loading rates. As previously mentioned at the beginning of this section the changes in the tensile properties of the CFRP as a result of possible strain rate sensitivity have been seen to be trivial, thus these changes are expected to have a minor influence on the response of the SHS strengthened with CFRP for the loading rates examined.

Table 2 Comparison between the internal energy for the static and impact tests

\begin{tabular}{|c|c|c|c|c|c|}
\hline \multirow{2}{*}{$\begin{array}{l}\text { Preloading } \\
(\%)\end{array}$} & \multirow{2}{*}{$\begin{array}{l}\text { CFRP } \\
\text { configuration }\end{array}$} & \multirow{2}{*}{$\begin{array}{l}\text { Transverse displacement } \\
(\mathrm{mm})\end{array}$} & \multicolumn{3}{|c|}{ Internal energy $(\mathrm{J})$} \\
\hline & & & Static & Impact & $\begin{array}{l}\text { Difference (impact - } \\
\text { static) }\end{array}$ \\
\hline 0 & - & 27 & 585.5 & 666.4 & 80.9 \\
\hline 50 & - & 27 & 455.5 & 610.7 & 155.2 \\
\hline 50 & Longitudinal & 27 & 489.6 & 655.8 & 166.2 \\
\hline 50 & Transverse & 27 & 455.1 & 640.1 & 185.0 \\
\hline 50 & Both & 27 & 501.5 & 673.6 & 172.1 \\
\hline
\end{tabular}

Table 3 Comparison between the theoretical mechanical properties of CFRP under various loading rates

\begin{tabular}{cccc}
\hline Loading rate $(\mathrm{m} / \mathrm{sec})$ & Tensile strength $(\mathrm{MPa})$ & Elastic modulus $(\mathrm{GPa})$ & Strain to failure \\
\hline $0.05 \times 10^{-3}$ & 1397.8 & 105.3 & 0.014 \\
4.43 & 1399.6 & 106.3 & 0.014 \\
Increase $(\%)$ & $0.1 \%$ & $1 \%$ & $0 \%$ \\
\hline
\end{tabular}

In parallel to the trend for absorbed energy, the variation between the energy absorbed in the impact and static tests for the samples strengthened in both directions was also greater than the corresponding values for the un-strengthened samples and remaining strengthened samples. It may be possible to 
conclude here that the CFRP effectiveness increased with a higher loading rate. This behaviour may have been partly caused by the strain rate sensitivity of the adhesive as indicated by [14] and [11], even if this might have made only a small contribution. It can be seen from Figure 13 showing the transverse displacement for samples C50 and SC50 against the strain gauge G1 reading that for the same transverse displacement the strain resulting from the impact test was greater than the corresponding value for the static test. Consequently, the CFRP provided an extra resistance to the local deformation, which helped to increase the effectiveness of the strengthening system. This trend seems to be opposite to that observed by [13] whereby following a series of axial compression tests on CFRP strengthened SHSs the effectiveness of CFRP reduced with higher stain rates. In the tests by [13], the reduction in the contribution of the CFRP strengthening technique was due to the extensive debonding that occurred in the impact tests. The adhesive material used in the study by [13] was a comparatively brittle material (MBrace) which other researchers $[12,14]$ have observed as being insensitive to strain rate changes. However, in the current experimental work, the adhesive employed is Araldite 420 which has been found by $[12,14]$ to be sensitive to strain rate and led to improved performance of CFRP strengthened steel joints at high strain rate.

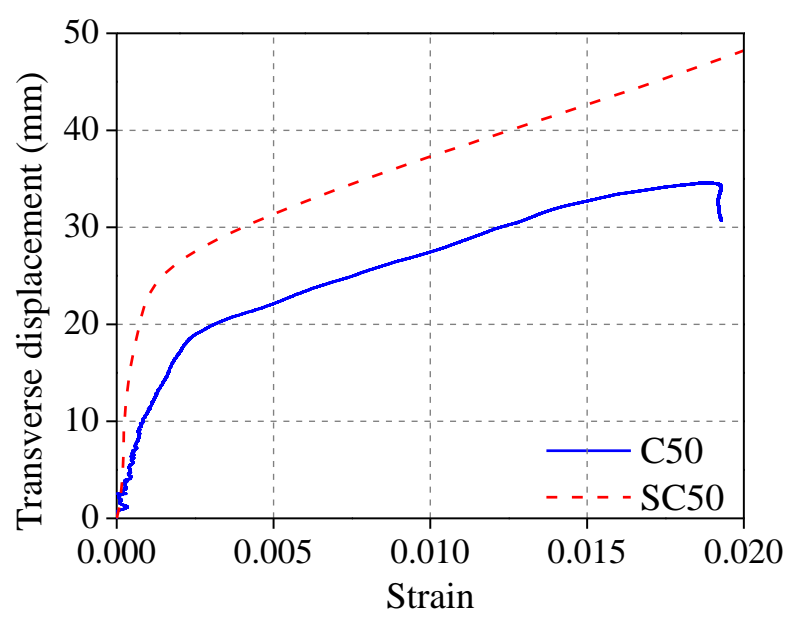

Figure 13. Transverse displacement against strain gauge G1 readings for samples C50 and SC50.

Another example of the comparison between the impact and static loading results was the strain value for the samples listed in Table 4 . The strain value in this table represents the strains from strain gauge G1. The comparison was made for a fixed internal energy value which is equal to $675 \mathrm{~J}$. This value is chosen because the maximum recorded absorbed energy for sample CLT50 was around $675 \mathrm{~J}$. It can be concluded from this table that the reduction in the strain value was more pronounced in the case of the impact loading rate. Similarly, another comparison can be made for the transverse displacement of the columns, as summarised in Table 5 It is seen from this table that in comparison with the unstrengthened columns, with the same internal absorbed energy $675 \mathrm{~J}$, the reduction in the maximum 
transverse displacement for the samples strengthened in both directions was $10 \%$ and $13 \%$ for the static and impact tests respectively.

Table 4 Strains in the transverse direction at the samples' mid-span in the static and impact tests with given absorbed energy

\begin{tabular}{lllll}
\hline Loading & $\begin{array}{l}\text { Absorbed } \\
\text { case }\end{array}$ & Strain & & \multirow{2}{*}{ Strain reduction $(\%)$} \\
\cline { 3 - 4 } & energy $(\mathrm{J})$ & Unstrengthened & Strengthened in both directions & \\
Static & 675 & 0.0181 & 0.0144 & 20 \\
Impact & 675 & 0.0127 & 0.0095 & 25 \\
\hline
\end{tabular}

Table 5 Comparison between the static and impact results with regard to the maximum transverse displacement

\begin{tabular}{lllll}
\hline $\begin{array}{l}\text { Loading } \\
\text { case }\end{array}$ & $\begin{array}{l}\text { Absorbed } \\
\text { energy }(\mathrm{J})\end{array}$ & \multicolumn{2}{l}{ Maximum transverse displacement $(\mathrm{mm})$} & $\begin{array}{l}\text { Transverse } \\
\text { displacement reduction } \\
(\%)\end{array}$ \\
\hline Static & 675 & 37 & Strengthened in both directions & 10 \\
Impact & 675 & 31 & 23 & 13 \\
\hline
\end{tabular}

\section{Conclusions}

In the present paper the effectiveness of CFRP strengthened steel SHS members under various loading rates was assessed by an experimental investigation. The influence of the following parameters was investigated: preloading level i.e. applied load / ultimate design load ( $0 \%$ and 50\%), loading rate $(0.05 \mathrm{~mm} / \mathrm{sec}$ and $4.43 \mathrm{~m} / \mathrm{sec})$ and CFRP configurations (fibres oriented in the longitudinal direction, transverse direction and both directions). From the obtained experimental results the following conclusions can be drawn:

- Full wrapping of CFRP was effective for strengthening SHS members subjected to quasistatic and impact loading rates. This conclusion is made by comparing the transverse displacement, plateau impact force and strain in the case of impact loading, while in the case of quasi-static loading, the load-transverse displacement and loading carrying capacity of samples were compared.

- Existing pre-compression load caused an increase in the transverse displacement and reduced the plateau impact force. The observation seems to be identical with that found in the case of the quasi-static loading rate where pre-compression caused a decrease in the lateral load carrying capacity of the tested sample.

- Regarding the CFRP configurations, it was found that applying the fibres in both the longitudinal and transverse directions had the greatest effectiveness compared to other strengthening configurations. The configuration with fibres oriented only in the transverse direction has the lowest contribution compared to other arrangements, even when the same overall volume of CFRP was used in all wrapping configurations. In quantitative terms,, in the case of the quasi-static loading rate, the increase in load carrying capacity of the sample strengthened with fibres oriented in both directions was $26 \%$ compared to the un-strengthened 
sample, while the enhancement was around $11 \%$ when the transverse orientation was used. The CFRP strengthening with fibres oriented in both directions had an ability to increase both flexural and shear resistance which normally govern global and local buckling of the sections respectively.

- The effectiveness of the CFRP in strengthening the tested SHS members increased with a high loading rate. However, the observed increase in the strengthening effectiveness was relatively small because the impact test undertaken was with a relatively low impact velocity. This observation is not in agreement with that found by [13] and may be due to the use of a more ductile, strain rate dependent adhesive material in the current experiments.

The preceding discussion demonstrates the potential effectiveness of the CFRP strengthening method in impact situations. The work presented here is focussed on relatively small SHS members, further study on larger scale members is required in order to determine whether the CFRP strengthening method remains effective and economic when scaled up to the type of sections seen in everyday building and civil engineering structures. Another limitation of the present study is that accurate separation of the energy absorbed by local deformation and that by global deformation was not possible in the experiment. Addressing the above limitations forms part of the on-going research of the authors.

\section{Acknowledgments}

Our thanks to the Ministry of Higher Education and Scientific Research in Iraq for funding this research. The authors wish to acknowledge the technical staff in the School of Mechanical, Aerospace and Civil Engineering, University of Manchester, for facilitating the experimental work.

\section{References}

[1] Hmidan A, Kim YJ, Yazdani S. CFRP repair of steel beams with various initial crack configurations. Journal of composites for construction 2011;15:952-62.

[2] Kadhim M. Effect of CFRP plate length strengthening continuous steel beam. Construction and Building Materials 2012;28:648-52.

[3] Colombi P, Poggi C. An experimental, analytical and numerical study of the static behavior of steel beams reinforced by pultruded CFRP strips. Composites Part B: Engineering 2006;37:64-73.

[4] Kadhim M, Wu Z, Cunningham L. FE modelling of CFRP strengthened steel members under impact loads. Proceedings of the 24th UK Conference of the Association for Computational Mechanics in Engineering, Cardiff, 31 March- 01 April 2016. p. 343-6.

[5] Kadhim M, Wu Z, Cunningham L. Modelling impact resistance of polymer-laminated steelwork. Proceedings of the Institution of Civil Engineers - Engineering and Computational Mechanics 2017; 170:7-24

[6] Shaat A, Fam AZ. Slender steel columns strengthened using high-modulus CFRP plates for buckling control. Journal of composites for construction 2009;13:2-12. 
[7] Silvestre N, Young B, Camotim D. Non-linear behaviour and load-carrying capacity of CFRPstrengthened lipped channel steel columns. Engineering structures 2008;30:2613-30.

[8] Alam MI, Fawzia S. Numerical studies on CFRP strengthened steel columns under transverse impact. Composite Structures 2015;120:428-41.

[9] Kadhim M, Wu Z, Cunningham L. Experimental study of CFRP strengthened steel columns subject to lateral impact loads. Composite Structures 2018;185:94-104.

[10] Alam MI, Fawzia S, Zhao X-L, Remennikov AM. Experimental Study on FRP-Strengthened Steel Tubular Members under Lateral Impact. Journal of composites for construction 2017;21:04017022.

[11] Al-Mosawe A, Al-Mahaidi R, Zhao X-L. Bond behaviour between CFRP laminates and steel members under different loading rates. Composite Structures 2016;148:236-51.

[12] Al-Zubaidy HA, Zhao X-L, Al-Mahaidi R. Dynamic bond strength between CFRP sheet and steel. Composite Structures 2012;94:3258-70.

[13] Bambach M, Jama H, Elchalakani M. Static and dynamic axial crushing of spot-welded thinwalled composite steel-CFRP square tubes. International Journal of Impact Engineering 2009;36:1083-94.

[14] Al-Zubaidy HA, Zhao X-L, Al-Mahaidi R. Mechanical characterisation of the dynamic tensile properties of CFRP sheet and adhesive at medium strain rates. Composite Structures 2013;96:153-64.

[15] Kadhim M, Wu Z, Cunningham L. Effects of loading rate on the behaviour of CFRP strengthened steel members. Fourth International Conference on Smart Monitoring, Assessment and Rehabilitation of Civil Structures, 13-15 September 2017.

[16] BSI. BS EN 1993-1-1: Eurocode 3: Design of steel structures - Part 1-1: General rules and rules for buildings. London: British Standards Institution, 2005.

[17] ASTM. Standard test methods for tension testing of metallic materials. E8/E8M. West Conshohocken, PA: ASTM, 2009.

[18] ASTM. Standard Test Method for Tensile Properties of Polymer Matrix Composite Materials. D3039 / D3039M. West Conshohocken, PA: ASTM, 2000.

[19] Huntsman. Structural adhesives aerospace adhesives araldite 420A/B. Switzerland: Datasheet, Huntsman Advanced Materials GmbH, 2009.

[20] Zeinoddini M, Parke G, Harding J. Axially pre-loaded steel tubes subjected to lateral impacts: an experimental study. International Journal of Impact Engineering 2002;27:669-90.

[21] Chen C, Zhao Y, Li J. Experimental Investigation on the Impact Performance of Concrete-Filled FRP Steel Tubes. Journal of Engineering Mechanics 2014;141:04014112.

[22] Shakir A, Guan Z, Jones S. Lateral impact response of the concrete filled steel tube columns with and without CFRP strengthening. Engineering structures 2016;116:148-62.

[23] Jones N. Structural impact. Cambridge: Cambridge University Press, 1997.

[24] Harding J, Welsh LM. A tensile testing technique for fibre-reinforced composites at impact rates of strain. Journal of Materials Science 1983;18:1810-26.

[25] Hallett S, Ruiz C. Material characterization tests and modelling of carbon fibre T300/914 at impact rates of strain. Le Journal de Physique IV 1997;7:C3-465-C3-70. 